\title{
MÉTRICA Y POÉTICA DE ANTONIO COLINAS
}

\section{Clara Isabel MARTÍNEZ CANTÓN}

(Sevilla: Rhythmica, 2011, Anejos IV, 336 págs.)

Muchos son los manuales, ensayos y artículos que abordan la obra poética de Antonio Colinas. Del mismo modo, numerosos son los que estudian su otra producción literaria. Sin embargo escasean los trabajos centrados exclusivamente en la métrica del poeta. Evoquemos desde aquí los del profesor José Enrique Martínez Fernández en la revista Rhythmica (2004. «Armonía y ritmo en Antonio Colinas: ajustes métricos en Noche más allá de la noche». Rhythmica. Revista Española de Métrica Comparada II, 137-148; 2006. «Oscuro oboe de bruma... Métrica, ritmo e interpretación». Rhythmica. Revista Española de Métrica Comparada III-IV, 181-194), este último precisamente escrito en colaboración con la autora, Clara Isabel Martínez Cantón. Por ello, bienvenida sea esta obra que ofrece una visión rigurosa y seria de uno de los aspectos más importantes de la poesía de Colinas.

En su Métrica y poética de Antonio Colinas, su autora profundiza de una manera sistemática en cada uno de los elementos característicos de la poesía: la métrica, el acento, la pausa, los tipos de rima y los versos. No cabe duda alguna del rigor: definitivos son los cuadros y tablas con los que concluye todos los apartados y capítulos en que ha estructurado su libro. En varios cuadros (pp. 52-67) expone el estudio estadístico realizado a todas las variedades 
de encabalgamiento en cada entrega poética de Colinas, ya por las unidades escindidas, ya por la longitud de estas. Y especial interés ofrece su valoración del contra-encabalgamiento abrupto, denominación que Isabel Paraíso toma prestada de la lírica francesa y con la que designa el encabalgamiento cuyo sintagma encabalgado es breve y queda delimitado por una pausa interior. Clara Isabel Martínez Cantón concluye que dicho encabalgamiento tiene una presencia que está en torno al $12 \%$ en la obra de Colinas. En una tabla (p. 169) recoge las distintas combinaciones y medidas de versos en los diferentes poemarios de Colinas. En otra (p. 170) el porcentaje del uso de los versos largos compuestos. Y en otras, en fin, cuenta los tipos de versos utilizados por el poeta en los diferentes libros de poesía aparecidos hasta la fecha.

Sustanciosas son asimismo las conclusiones que jalonan la lectura del libro. Clara Isabel Martínez Cantón afirma que la sinalefa recae generalmente sobre la quinta sílaba cuando el poeta opta por los endecasílabos. Asegura que los finales agudos, llanos o esdrújulos son independientes al tema abordado por Antonio Colinas en el poema. Ratifica que hay acentos rítmicos y extrarrítmicos en la misma proporción y que esta se mantiene a lo largo de toda la producción poética de Colinas. Y añade la autora que este hecho permite una «recitación más afectada o bien busca destacar elementos expresivos». Nos parece más cercana a la poesía y al pensamiento del poeta esta última opción.

Especial interés reviste el estudio de la pausa en la poesía de Antonio Colinas. Es sin duda el elemento al que tradicionalmente se presta menor atención, seguramente debido a la dificultad que plantea su análisis. Por esta razón, valoramos muy positivamente la valentía de Clara Isabel Martínez Cantón. La pausa en el poeta bañezano adquiere gran singularidad, pues como sostiene la autora en su libro, está estrechamente ligada a la respiración, tema este de enorme importancia en la obra coliniana. Se pone, pues, de relevancia el empleo del encabalgamiento suave, mucho más armónico, en cualquiera de sus posibilidades, léxica, sirremática u oracional. Los encabalgamientos abruptos o los estróficos apenas aparecen. Siempre hemos afirmado que Colinas es un poeta que busca la armonía, que sigue la estela de Orfeo y en este sentido, su poesía discurre a través de moldes y ritmos muy clásicos. Así por tanto, determinadas licencias rupturistas resultan impensables en sus versos.

Cuando se aborda el estudio de una obra poética, la rima se torna uno de los aspectos más importantes, pues es el componente fundamental del verso. 
Y dado que su presencia no es obligatoria, Clara Isabel Martínez Cantón repara tanto en el uso que de la rima hace Colinas, como en aquellos poemas en los que prescinde de ella. La autora estudia a fondo el endecasílabo y el alejandrino, los versos más empleados por Antonio Colinas. Con respecto al primero, en Métrica y poética de Antonio Colinas se incluyen unas exhaustivas tablas con la utilización y frecuencia del endecasílabo y sus subtipos. Su autora llega a la conclusión de que es más frecuente el endecasílabo a maio$r i$ y sus variantes, principalmente en 4-6-10, al que considera un subtipo $a$ minori. Sin embargo, Miguel Ángel Márquez lo considera un tipo independiente y lo denomina endecasílabo horaciano, lo que nos parece más apropiado en el caso concreto de Colinas, pues siempre hemos defendido la tesis de que su poesía y su vida se encuentran en íntima unión, de que su poesía y su pensamiento se hallan perfectamente trabados. Antonio Colinas presta especial cuidado entre los aspectos más externos de su poesía y el contenido de la misma.

Asimismo, consideramos a Colinas un poeta arraigado en la tradición hispánica y gran conocedor de la obra de Rubén Darío. Seguramente ésta sea la razón por la que opta en numerosas ocasiones por el endecasílabo dactílico, introducido por el vate nicaragüense y acentuado en 4-7-10. Por lo que nos parece aventurado afirmar, aunque así lo justifique, que Colinas «no es plenamente consciente de su uso, pero capta su sonoridad».

Por lo que respecta al empleo del verso alejandrino, la autora señala la existencia de los diferentes tipos en la poesía de Antonio Colinas desde sus primeros poemas, aunque concluye en la preferencia por los tipos yámbico y polirrítmico, pues son los más frecuentes. E indica la gran flexibilidad que ofrece este verso llegado a nuestra literatura a través de la influencia francesa a partir del Modernismo. En este sentido, Clara Isabel Martínez Cantón concluye en la preferencia de Colinas en sus últimas entregas por la silva libre impar y por el verso libre.

En cuanto a la utilización que Colinas hace del verso libre, señala la autora que se trata de un proceso lento por el que opta en sus últimas etapas, pues en las primeras «es completamente fiel a los versos tradicionales». Se pregunta a qué se debe este giro, ya que algunos estudiosos entienden el verso libre como una mayor libertad expresiva, una reafirmación de la originalidad y de la individualidad frente a la creación en serie y a la industrialización del siglo XX (Gili Gaya, Estudios sobre el ritmo, Madrid: Istmo, 1993, con edición de Isabel Paraíso) o como el reflejo de una sociedad caótica en la que destaca la desarticulación del orden (M. ${ }^{a}$ V. Utrera, «Tipografía y verso 
libre». Rhythmica. Revista Española de Métrica Comparada II, 2004, págs. 251-273). Sin embargo, Clara Isabel Martínez Cantón lo interpreta como el paso de «la visión armónica tradicional a una inarmónica, conflictiva», dado que en el caso concreto de Antonio Colinas el poeta se mueve entre «la dificultad para mantener la armonía y las tensiones entre extremos». Sin embargo, a nuestro parecer, Colinas se muestra también en esta ocasión, deudor de nuestra tradición literaria. La silva fue usada ya por Góngora, uno de los poetas favoritos del bañezano. La libertad y la expresividad que busca en su madurez, se la proporciona esta silva libre, por otro lado tan empleada en poetas más recientes, como Juan Ramón Jiménez, uno de los maestros indiscutibles para Colinas. La doctora Martínez afirma que «no existe voluntad de ruptura», que tampoco «hay ansia de innovación métrica» en Colinas cuando se inclina por el verso libre. En efecto, también lo consideramos así, pues creemos que la ruptura en la poesía de Colinas está en aspectos menos externos, más próximos a la temática. Y con la autora del libro coincidimos plenamente. Este ritmo viene marcado por las repeticiones y por los paralelismos, no exclusivamente por las licencias métricas.

Otro gran acierto que plantea este libro es el estudio pormenorizado de los versos de arte menor en la poesía de Antonio Colinas, en cuyo empleo ve la autora «una necesidad de síntesis, brevedad y concisión, un afán de unidad».

Por otro lado, repara en los poemas en prosa que se incluyen en la tercera parte de Jardín de Orfeo. La autora se cuestiona si realmente son poemas, llegando a la conclusión de que «el poema en prosa coliniano se ajusta sin ningún problema a las definiciones más estrictas que existen sobre este género». A nuestro parecer tampoco hay ninguna duda. Los recursos estilísticos, el ritmo, las repeticiones y los paralelismos así lo corroboran. Luis Moliner reparaba en la alternancia de un poema escrito en verso seguido por otro en prosa, y veía brotar la sangre y el agua, en definitiva la vida. En esta conjunción entre verso y prosa logra Colinas el todo, la unidad, la armonía. En efecto, nunca nada es fruto del azar en la obra poética de Antonio Colinas. Esta tercera y última parte del poemario referido no sólo da título al libro, «Jardín de Orfeo», sino que ofrece algunos de los poemas más puramente místicos escritos por este poeta que entiende la mística desde una raíz universal. Alterna por lo tanto poemas ya en verso, ya en prosa, pues busca una única dicción. Por otro lado, ya antes se atrevieron con esta innovación métrica otros poetas, no sólo Juan Ramón o Novalis, también el más rompedor Darío, el de Prosas profanas. 
Queda pues de manifiesto, a lo largo del libro, la maestría con que Colinas se enfrenta al hecho poético. Maestría que se ofrece tanto en versos medidos, cuidados, regulares, como en versos libres muy alejados de la «prosa cortada a pedazos», versos que en todo momento reflejan un ritmo profundo que enlaza con la temática tratada, o poemas en prosa que ponen de manifiesto su enorme pericia mediante repeticiones y paralelismos, ya sintácticas, ya fonéticas, ya semánticas. Es Antonio Colinas poeta que busca incansable la armonía, la perfección, el equilibrio. Y es precisamente su voz la que cierra este libro. La autora ha incluido varios anexos. El primero de los cuales es la «Entrevista sobre métrica a Antonio Colinas. 15 de octubre de 2010». Asimismo, ofrece los cambios introducidos por el poeta en sus diferentes poemarios con la aparición de su Obra poética completa, en Siruela en 2011. Y por último ofrece una buena bibliografía que versa tanto sobre aspectos de métrica, como sobre la poesía de Antonio Colinas.

Indudablemente y hasta la publicación de nuevos estudios que se centren en la obra poética de Colinas, éste es el manual definitivo.

Susana Agustín 
